\title{
Population History of a Hydrothermal Vent-Endemic Gastropod Alviniconcha hessleri in the Mariana Trough
}

\author{
Hiroka Hidaka, Tomomi Ogura, Hiromi Watanabe, Yasunori Kano, and \\ Shigeaki Kojima
}

\begin{abstract}
Molecular evolutionary rate of the COI (cytochrome $c$ oxidase subunit I) gene in the vent endemic genus Alviniconcha (Gastropoda: Provannidae) was estimated to be $0.69 \%$ per million year based on GTR (General time-reversible) + G (Gamma) + I (Proportion Invariant) distances and hypothesized divergence dates of 59-64 Ma (million years ago) between Alviniconcha and its sister genus Ifremeria. The population history of A. hessleri, an endemic species to the Mariana Trough, the northwestern Pacific, was reconstructed by analyzing the nucleotide sequences of two fragments of mitochondrial DNA and an intron region of a nuclear gene for ATPS $\beta$ (ATP Synthetase subunit $\beta$ ) and by extrapolating the estimated COI rate. Two genetically deviated $A$. hessleri groups with different patterns of geographical distribution were recognized in the analysis of the mitochondrial DNA and their age of divergence was estimated to be $0.91 \mathrm{Ma}$ by the coalescent theory-based analysis of the nuclear gene data. The present geographical distributions of the two groups suggest that their ancestral populations were isolated in the central and southern Mariana Trough, respectively. Rapid expansion (increase of the population size) was suggested to have occurred in both groups at 0.26 and $0.17 \mathrm{Ma}$, respectively. Periodical changes of hydrothermal activity have apparently controlled the isolation and expansion of the local populations.
\end{abstract}

\section{Keywords}

Alviniconcha hessleri $\bullet$ ATP Synthetase subunit $\beta \bullet$ Hydrothermal vent $\bullet$ Intron $\bullet$ Mitochondrial DNA • Phylogeography

H. Hidaka • S. Kojima $(\triangle)$

Graduate School of Frontier Sciences, The University of Tokyo, Chiba 277-8563, Japan

Atmosphere and Ocean Research Institute, The University of Tokyo, Chiba 277-8564, Japan

e-mail:kojima@aori.u-tokyo.ac.jp

T. Ogura

Japan Agency for Marine-Earth Science and Technology, Kanagawa 237-0061, Japan

Graduate School of Marine Science and Technology, Tokyo University of Marine Science and Technology, Tokyo 108-8477, Japan

H. Watanabe

Japan Agency for Marine-Earth Science and Technology, Kanagawa 237-0061, Japan

Y. Kano

Atmosphere and Ocean Research Institute, The University of Tokyo, Chiba 277-8564, Japan 


\subsection{Introduction}

Since the discovery of the first deep-sea hydrothermal field in the late 1970s, many hydrothermal-vent endemic species have been reported from various vent fields over the world (Rogers et al. 2012). Hydrothermal vent fields are generally unstable environments; the activities sometimes rapidly abate, cease or increase to cause the catastrophic explosion and the longevity of a single vent is estimated to be no more than 10,000 years (Vrijenhoek 2010). Thus, species endemic to such environments are expected to have abilities to disperse and colonize other vent sites. Comparison of the population history of vent-endemic faunal groups would provide valuable information to understand mechanisms underlaying the evolution of such animals. Recent development of phylogeographic analyses including the coalescent theory-based methodologies has enabled us to investigate population history in more detail (Kuhner 2008; Ho and Shapiro 2011). On the other hand, new geochemical analyses of hydrothermal sulfides and sulfate minerals, which reflect magmatic activities of their places of production, are also being developed to reconstruct the historical changes of hydrothermal activities more precisely (Ishibashi et al. 2009, Chap. 23). Results obtained from biological and geochemical evidences need to be integrated for more accurate understanding of history of hydrothermal ecosystems and for the improvement of each method (Kumagai et al. Chap. 5).

In this chapter, the population history of a hydrothermal vent-endemic snail Alviniconcha hessleri is reconstructed. Alviniconcha snails have highly specialized morphological and ecological characteristics to adapt the vent environments with chemoautosynthtic endosymbiotic gamma- or epsilonproteobacteria (Suzuki et al. 2006). Alviniconcha hessleri dominates as an endemic species in hydrothermal areas in the Mariana Trough, the northwestern Pacific. This species was described based on specimens collected at the Alice Springs site (3,600 $\mathrm{m}$ depth) in the central Mariana Trough (Okutani and Ohta 1988). The second habitat of this species was discovered at the Forecast Vent site (1,470 m depth) in the southern Mariana Trough (Johnson et al. 1993). During the first decade of the twenty-first century, various hydrothermal vent fields have been discovered in the southernmost part of the Mariana Trough. Among them, A. hessleri has been reported from three sites, namely, the Snail (=Fryer), Archaean, and Pika sites. The Snail site (2,850 m depth) is situated on the South Mariana Backarc Spreading Center while the Archaean $(2,990 \mathrm{~m}$ depth) and Pika $(2,770 \mathrm{~m}$ depth) sites were discovered on off-axis seamounts (Wheat et al. 2003; Urabe et al. 2004; Kakegawa et al. 2008; Yoshikawa et al. 2012). These vent sites are distributed almost on a straight line from the ridge axis to the off- ridge. Although the present hydrothermal activity of the Mariana Trough is estimated to have started about $7 \mathrm{Ma}$ (Stern et al. 2003), detailed historical changes in the activity have been traced back only to 12,000 years ago by the geochemical approach (Stüben et al. 1994; Takamasa et al. 2013; Ishibashi et al., Chap. 23).

Johnson et al. (2010) estimated phylogenetic relationships and deviation dates among provannid gastropods including Alviniconcha snails, with the Bayesian evolutionary analysis on the basis of nucleotide sequences from the mitochondrial COI (cytochrome $c$ oxidase subunit I), $12 \mathrm{~S}$ and $16 \mathrm{~S}$ ribosomal RNA (rRNA) genes and nuclear Histone $\mathrm{H} 3$ and $18 \mathrm{~S}$ and $28 \mathrm{~S}$ rRNA genes. They calibrated molecular clocks based on a hypothetical age of vicariance between the Pacific and Atlantic deep-sea faunas at 15-16 Ma in prior to the closure of the Isthmus of Panama, or fossil records that suggest the divergence between Provanna and Desbruyeresia at 93-100 Ma and two outgroup Neptunea species at 33-37 Ma. Using this clock, the population history of $A$. hessleri can be estimated. However, the intraspecific molecular evolutionary rate is expected to be higher than intergeneric rates, as the estimate of rate decrease with enlargement of time-scale investigated due to the saturation of genetic mutations, which results in the overestimation of ages. The present study attempted to decrease this problem by calculating rates based on genetic distances between congeneric species.

This chapter report population history of A. hessleri in the Mariana Trough from 1 to 0.2 Ma revealed by phylogeographic analyses using adequate molecular evolutionary rate mentioned above and discuss changes of the hydrothermal activity during this period, which might have greatly contributed to the population dynamics of vent-endemic species.

\subsection{Materials and Methods}

\subsubsection{Evolutionary Rate of COI Gene in Alviniconcha}

The molecular evolutionary rate of the COI gene in Alviniconcha was estimated by analyzing sequences from additional species of the genus and other provannids under the GTR (General time-reversible) + G (Gamma) + I (Proportion Invariant) distances model and by extrapolating suggested divergence dates between Alviniconcha and Ifremeria in Johnson et al. (2010). Seven COI sequences published in Suzuki et al. (2006) were incorporated with 18 representative sequences from Johnson et al. (2010) and 25 operational taxonomic units (OTUs) with the length of 530 base pair (bp) were used in the succeeding Bayesian phylogenetic analysis. The genus Alviniconcha was represented by all the five known species (Hidaka et al. 
Table 26.1 List of samples used for population genetic analyses

\begin{tabular}{|c|c|c|c|c|c|c|}
\hline No. & Site & Coordinates & Depth (m) & Dive\# & Date & $N^{\mathrm{a}}$ \\
\hline 1 & Alice Springs & $18^{\circ} 13^{\prime} \mathrm{N}, 144^{\circ} 43^{\prime} \mathrm{E}$ & 3,600 & $6 \mathrm{~K} 153$ & 9 November 1992 & $20^{\mathrm{b}}(18)$ \\
\hline 2 & Forecast & $13^{\circ} 24^{\prime} \mathrm{N}, 143^{\circ} 55^{\prime} \mathrm{E}$ & 1,470 & $6 \mathrm{~K} 186$ & 22 October 1993 & $20^{\mathrm{b}}(13)$ \\
\hline 3 & Snail & $12^{\circ} 57^{\prime} \mathrm{N}, 143^{\circ} 37^{\prime} \mathrm{E}$ & 2,850 & $6 \mathrm{~K} 1228$ & 22 September 2010 & $20(18)$ \\
\hline 4 & Archaean & $12^{\circ} 56^{\prime} \mathrm{N}, 143^{\circ} 38^{\prime} \mathrm{E}$ & 2,990 & $6 \mathrm{~K} 1224$ & 9 September 2010 & $20(14)$ \\
\hline 5 & Pika & $12^{\circ} 55^{\prime} \mathrm{N}, 143^{\circ} 39^{\prime} \mathrm{E}$ & 2,770 & $6 \mathrm{~K} 1225$ & 10 September 2010 & $20(18)$ \\
\hline
\end{tabular}

${ }^{a}$ Numbers of specimens used for sequencing the ATP Synthetase subunit $\beta$ gene are shown in parentheses

${ }^{b}$ Nucleotide sequences of mitochondrial DNA were reported in Hidaka et al. (2013)

2013) to better correct the genetic distances between these ingroup OTUs, while only three conspecific individuals were included for the monotypic Ifremeria.

Bayesian tree reconstruction was performed with MrBayes 3.1.2 (Ronquist and Huelsenbeck 2003). The shape, proportion of invariant sites, state frequency and substitution rate parameters were estimated for each codon position separately. Two parallel runs were made for $10,000,000$ generations (with a sample frequency of $1,000)$, using the default value of four Markov chains. The first 5,000 trees for each run were discarded to ensure the four chains reached stationarity by referring to the average standard deviation of split frequencies (Ronquist and Huelsenbeck 2003). The consensus tree and posterior probabilities (PP) were computed from the remaining 10,000 trees $(5,000$ trees, 2 runs).

\subsubsection{Population History of Alviniconcha hessleri}

The specimens of $A$. hessleri used for population genetic analyses in this study were collected by the submersible SHINKAI 6500 of the Japan Agency for Marine-Earth Science and Technology (JAMSTEC; Table 26.1). Sampling at the Snail, Archaean, and Pika sites in the southernmost area of the Mariana Trough was conducted as a part of the TAIGA Project. Total genomic DNA was extracted from the foot tissue of sixty specimens from the three sites with a DNeasy Tissue Extraction Kit (Qiagen, Valencia, CA). DNA samples from a previous study (Kojima et al. 2001) were used for populations at the Alice Springs and Forecast sites. The extracted DNA was treated with GeneReleaser (BioVenture Inc., Murfreesboro, TN) to sequester the products of cell lysis that might have inhibited polymerase activity.

Three fragments were amplified for each of the newly collected specimens from the southernmost Mariana Trough by polymerase chain reaction (PCR) with the extracted DNA as a template and Takara Ex Taq Hot Start Version (Takara Bio Inc., Shiga, Japan). These included two mitochondrial DNA fragments for the cytochrome $c$ oxidase subunits I (COI) and a region spanning from the $\mathrm{tRNA}^{\mathrm{Met}}$ gene to the $12 \mathrm{~S}$ rRNA gene, as well as an intron region of a nuclear gene for ATP Synthetase subunit $\beta$ (ATPS $\beta$ ). The COI fragment was amplified using primers LCO1490 (5'-GGTCAACAAATCATAAAGATATTGG-3') (Folmer et al. 1994) and COI-6 (5'GGRTARTCNSWRTANCGNCGNGGYAT-3') (Shimayama et al. 1990). The second fragment, which contains the tRNA ${ }^{\text {Met }}$, $\mathrm{tRNA}^{\mathrm{Trp}}$, $\mathrm{tRNA}^{\mathrm{Tyr}}$, tRNA ${ }^{\mathrm{Cys}}, \mathrm{tRNA}^{\mathrm{Gln}}, \mathrm{tRNA}^{\mathrm{Gly}}, \mathrm{tRNA}^{\mathrm{Glu}}$, and $12 \mathrm{~S}$ rRNA genes and six non-coding regions, was amplified using a primer set AlIfCOII-1 (5'-GGGCATCARTGATAYTGRAG-3') (Hidaka et al. 2013) and AlIf12S-1R $\left(5^{\prime}\right.$-GTCTAAAGCACCGCCAAGCCC-3') (Hidaka et al. 2013) or another set AlIfATP6-1 (5'-TATACAATTTTTGARTTYGG-3') (Hidaka et al. 2013) and AlIf12S-2R (5'TATAYTTWYAAGTCAGAGCCAAGC- $3^{\prime}$ ) (Hidaka et al. 2013). This region has been shown to provide much more information about the genetic structure of $A$. hessleri than the COI gene does (Hidaka et al. 2013). PCR conditions for the two mitochondrial DNA fragments were as follows: incubation at $94{ }^{\circ} \mathrm{C}$ for $2 \mathrm{~min}$, followed by 40 cycles of incubation at 92,50 , and $72{ }^{\circ} \mathrm{C}$ for $40 \mathrm{~s}, 1 \mathrm{~min}$, and $90 \mathrm{~s}$, respectively, and a final extension at $72{ }^{\circ} \mathrm{C}$ for $7 \mathrm{~min}$. DNA fragments containing the intron region of the nuclear ATPS $\beta$ gene were amplified using a primer ATPS $\beta \mathrm{f} 1$ (5'-CGTGAGGGNAAYGATTTHTACCATGAGATGAT-3') (Jarman et al. 2002) in combination with either ATPS $\beta r 1$ TACTTGCTTGGNGGDCCRCGGGCACGGGC-3') (Jarman et al. 2002) or ATPS $\beta r 2$ (5'-ACACCTGCACAAATCACCAC- $3^{\prime}$; synthesized on the basis of determined sequences). PCR conditions for this fragment were as follows: incubation at $94{ }^{\circ} \mathrm{C}$ for $2 \mathrm{~min}$, followed by 35 cycles of incubation at 94,54 , and $72{ }^{\circ} \mathrm{C}$ for $20 \mathrm{~s}, 1 \mathrm{~min}$, and $1 \mathrm{~min}$, respectively. For specimens from the Alice Springs and Forecast Vent sites, only the third fragment was newly amplified as nucleotide sequences of two mitochondrial DNA fragments have been determined and published elsewhere (Kojima et al. 2001; Hidaka et al. 2013).

Each PCR product was incubated with ExoSAP-IT (United States Biochemical, Cleveland, $\mathrm{OH}$ ) at $37{ }^{\circ} \mathrm{C}$ for $15 \mathrm{~min}$ to digest the unused primers and nucleotides and at $80{ }^{\circ} \mathrm{C}$ for $15 \mathrm{~min}$ to deactivate ExoSAP, used in cycle sequencing reactions performed with a BigDye Terminator Cycle Sequencing Kit Version 3.0 (Applied Biosystems Inc., Foster City, CA), and sequenced on an automated sequencer 
(ABI3130; Applied Biosystems) with the same primers as used in PCR. Low quality ends were trimmed from the obtained sequences and the final dataset comprised $491 \mathrm{bp}$ and 631-633 bp for the COI gene and the region spanning from the tRNA ${ }^{\text {Met }}$ gene to the $12 \mathrm{~S}$ rRNA gene, respectively. The ATPS $\beta$ intron dataset was represented by nucleotide sequences of 194-226 bp from a limited number of individuals, where genotype could be determined through direct-sequencing; those yielded multiple amplicons with more than one substitutions and/or indels were excluded from the succeeding coalescence theory-based analyses. The nucleotide sequences determined in the current study were deposited in the DDBJ/EMBL/GenBank databases under the accession numbers AB874407-874415 (COI), AB874416-874443 (tRNA ${ }^{\text {Met }}-12$ SrRNA), and AB874444-874468 (ATPS $\beta$ ).

Haplotype networks were constructed on the basis of differences in the nucleotide sequences of the mitochondrial datasets with the median-joining method implemented in Network version 4.6.1.0 (Bandelt et al. 1999). Differences in the frequencies of haplotypes between populations were evaluated using the exact test of population differentiation (Raymond and Rousset 1995) in the Arlequin software package version 3.5.1.2 (Excoffier and Lischer 2010). This software package was also used to estimate the unbiased fixation index, $F_{\mathrm{ST}}$ (Weir and Cockerham 1984) and to test the significance of the $F_{\mathrm{ST}}$ values by nonparametric permutation with 10,000 runs.

The same mitochondrial datasets were also analyzed to infer the demographic history of the species based on the distribution of pairwise sequence differences. Historical population expansion (a rapid increase of population size) was assessed by performing mismatch distribution analysis (Rogers and Harpending 1992; Rogers 1995) in Arlequin. Whether or not a given population has recently experienced a sudden expansion was evaluated by testing the null hypothesis that the mismatch distribution expected under the sudden expansion model is different from the observed distribution. If the population was considered to have recently experienced a sudden expansion, the time from the expansion $(t)$ was estimated according to the relationship $\tau=2 t u$, where $\tau$ is the mode of the distribution and $u$ is the mutation rate of a sequence calculated as $u=\mu k$ (where $\mu$ is the mutation rate per nucleotide and $k$ is the number of nucleotides) (Rogers and Harpending 1992). Moreover, Tajima's $D$ test (Tajima 1983) and Fu's $F_{\text {s }}$ test (Fu 1997) of neutrality were performed in Arlequin to further evaluate the possible events during population expansion. A population that has experienced expansion generally shows a significant negative Tajima's $D$ value; $F_{\mathrm{s}}$ is also sensitive to population expansion, which generally leads to large negative $F_{\mathrm{s}}$ values (Fu 1997).
The distribution of the posterior probabilities for the deviation date between populations of A. hesssleri were estimated using the ATPS $\beta$ intron dataset and Bayesian coalescent inference (Hey and Wakeley 2001) implemented in the program IM (Hey and Nielsen 2007). The prior distributions of parameters were adjusted as a function of what was observed in the first run with the default settings according to the program documentation. Replicate runs with different seed numbers were conducted to ensure each run had approximately the same results. Ten million steps were sampled for each run after a burn-in of $1,000,000$ steps. The converged ten runs with the complete posterior distributions of all parameters within the prior distributions were used for the final divergence time estimates.

The mutation rates of the tRNA ${ }^{\text {Met }}-12 \mathrm{~S}$ rRNA and ATPS $\beta$ intron regions were approximated by comparing Kimura-corrected average pairwise distances (Kimura 1980) for these regions and the COI gene among the individuals of $A$. hessleri and by extrapolating the estimated evolutionary rate for the latter gene in the entire Alviniconcha (see above).

\subsection{Results}

\subsubsection{Evolutionary Rate of COI Gene in Alviniconcha}

The Bayesian phylogenetic reconstruction under the GTR + $\mathrm{G}+\mathrm{I}$ model estimated COI genetic distances between the six individuals of Alviniconcha and three of Ifremeria nautile $i$ to be $0.8088-0.8514$ with an average of 0.8264 (Fig. 26.1). The divergence date for the split between Alviniconcha and Ifremeria was estimated either at 64.4 Ma (31.4-98.9 Ma: $95 \%$ highest probability density interval) or 59.2 Ma (18.8-74.5 Ma) using fossil calibration points or the hypothesized vicariance of deep-sea taxa across the Isthmus of Panama, respectively (Johnson et al. 2010). Assuming that reasonably well corrected distances were observed in the present Bayesian phylogram and the two lineages leading to Alviniconcha and Ifremeria evolved at an equal pace, the substitution rate of their COI gene was calculated to be $0.64 \%$ per million years (My) (95\% confidence range: $0.42-1.32 \% / \mathrm{My}$ ) with the fossil dates or $0.70 \% / \mathrm{My}(0.55-2.19 \% / \mathrm{My})$ with the vicariance calibration. As the two estimates were similar to each other, the average value $(0.67 \% / \mathrm{My})$ was used in the following assessment of population history of $A$. hessleri. This average value roughly corresponded to the lower limit of the range of COI evolutionary rates for animal lineages (0.7-1.2 \%/My) reviewed by Wilke (2003). 
Fig. 26.1 Bayesian phylogram of 22 provannid and three outgroup gastropods, reconstructed from the 530-bp alignment of the cytochrome $c$ oxidase subunit I gene. Numerals on branches indicate Bayesian posterior probabilities, shown as percentage for values above $50 \%$. See Johnson et al. (2010) and Hidaka et al. (2013) for the details of the study specimens



Table 26.2 The genetic diversity of five populations of Alviniconcha hessleri estimated from two mitochondrial regions

\begin{tabular}{|c|c|c|c|c|c|}
\hline Region & Vent site & $N$ & Haplotype & Gene diversity & Nucleotide diversity \\
\hline \multirow[t]{5}{*}{$\mathrm{COI}$} & Alice Springs & 20 & 10 & $0.85 \pm 0.06$ & $0.00322 \pm 0.00223$ \\
\hline & Forecast & 20 & 10 & $0.91 \pm 0.04$ & $0.00398 \pm 0.00263$ \\
\hline & Snail & 20 & 6 & $0.52 \pm 0.13$ & $0.00177 \pm 0.00145$ \\
\hline & Archaean & 20 & 9 & $0.80 \pm 0.09$ & $0.00268 \pm 0.00195$ \\
\hline & Pika & 20 & 6 & $0.64 \pm 0.12$ & $0.00241 \pm 0.00180$ \\
\hline \multirow[t]{5}{*}{$\mathrm{tRNA}^{\mathrm{Met}}-12 \mathrm{SrRNA}$} & Alice Springs & 20 & 11 & $0.76 \pm 0.10$ & $0.01385 \pm 0.00894$ \\
\hline & Forecast & 20 & 12 & $0.92 \pm 0.04$ & $0.02729 \pm 0.01576$ \\
\hline & Snail & 20 & 11 & $0.89 \pm 0.05$ & $0.01894 \pm 0.01154$ \\
\hline & Archaean & 20 & 13 & $0.91 \pm 0.05$ & $0.01891 \pm 0.01152$ \\
\hline & Pika & 20 & 13 & $0.88 \pm 0.07$ & $0.01978 \pm 0.01197$ \\
\hline
\end{tabular}

\subsubsection{Population History of Alviniconcha hessleri}

Twenty-five and 53 types of sequences (haplotypes) were identified among a hundred individuals of $A$. hessleri in the COI gene and the fragment spanning from the tRNA ${ }^{\text {Met }}$ gene to the $12 \mathrm{~S}$ rRNA gene, respectively. The COI region contained 21 variable sites, eight of which were parsimoniously informative; the tRNA ${ }^{\text {Met }}-12$ S rRNA region had 50 variable and 26 parsimoniously-informative sites. The genetic diversity of populations of Alviniconcha hessleri at different five hydrothermal sites was estimated from two mitochondrial regions (Table 26.2). The unbiased $F_{\mathrm{ST}}$ and exact tests of population differentiation for a combined dataset of the two mitochondrial regions showed no significant genetic difference among populations from the five vent sites $(p>0.05)$ except between the Snail and Pika sites in the latter test $(p=0.047)$.

The above comparison between the two gene regions showed that the tRNA ${ }^{\text {Met }}-12 \mathrm{~S}$ rRNA fragment contained more informative signals than the COI gene as noted in a previous study (Hidaka et al. 2013). Indeed, genetically distinct groups were recognized only in the haplotype network of the former gene region: seven haplotypes construct a group (Group 2 in Fig. 26.2b), which is separated from another group constructed by 46 other haplotypes (Group 1 in Fig. 26.2b), by three substitutions. The two groups 


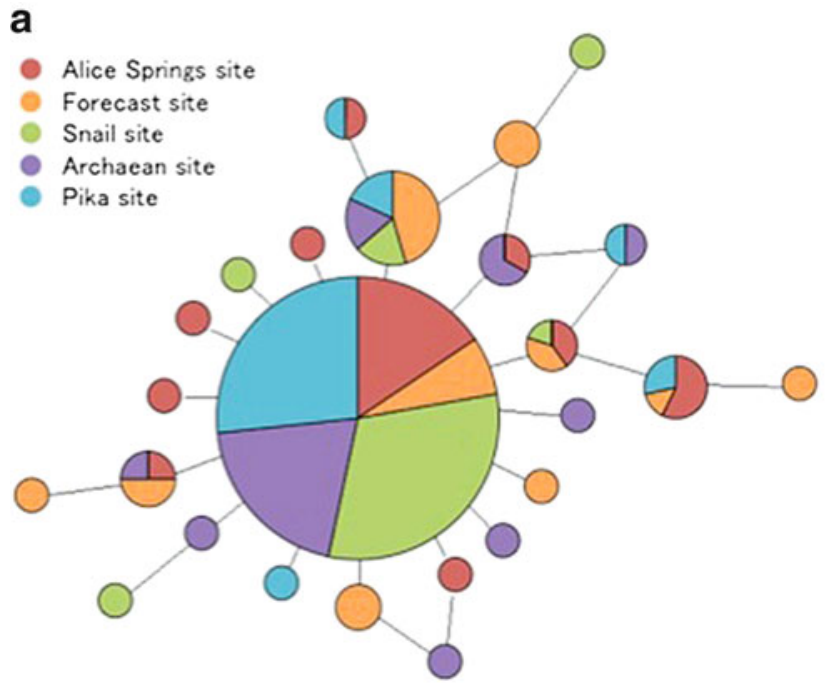

Fig. 26.2 Median-joining networks connecting haplotypes found in the five populations of Alviniconcha hessleri for the cytochrome $c$ oxidase subunit I gene (a) and the region spanning from the tRNA ${ }^{\mathrm{Met}}$ gene to the $12 \mathrm{~S}$ rRNA gene (b). Open circles denote missing

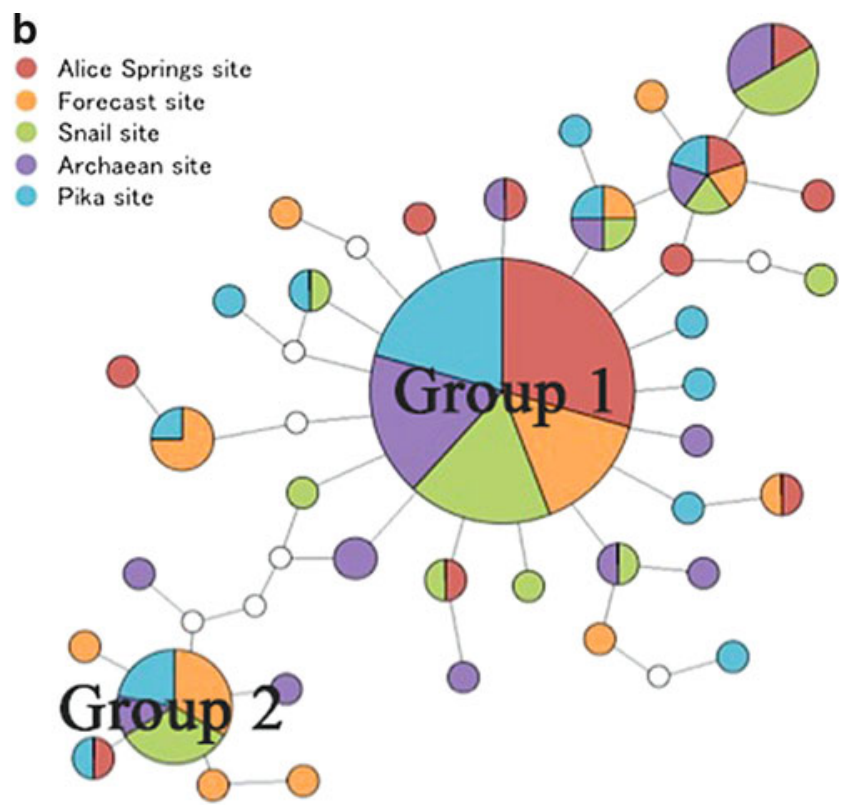

haplotypes. The areas of the colored circles are proportional to the frequency of each haplotype: the smallest ones represent single individuals. Two haplotype groups (separated by three missing haplotypes) were recognized in the network shown in (b)
Fig. 26.3 Mismatch distributions for two groups of Alviniconcha hessleri, the Group 1 (a) and Group 2 (b), based on combined nucleotide sequences of the gene for the cytochrome $c$ oxidase subunits I and the region spanning from the tRNA ${ }^{\text {Met }}$ gene to the $12 \mathrm{~S}$ rRNA gene. Lines: expected distribution for the sudden expansion model; bars: observed distribution
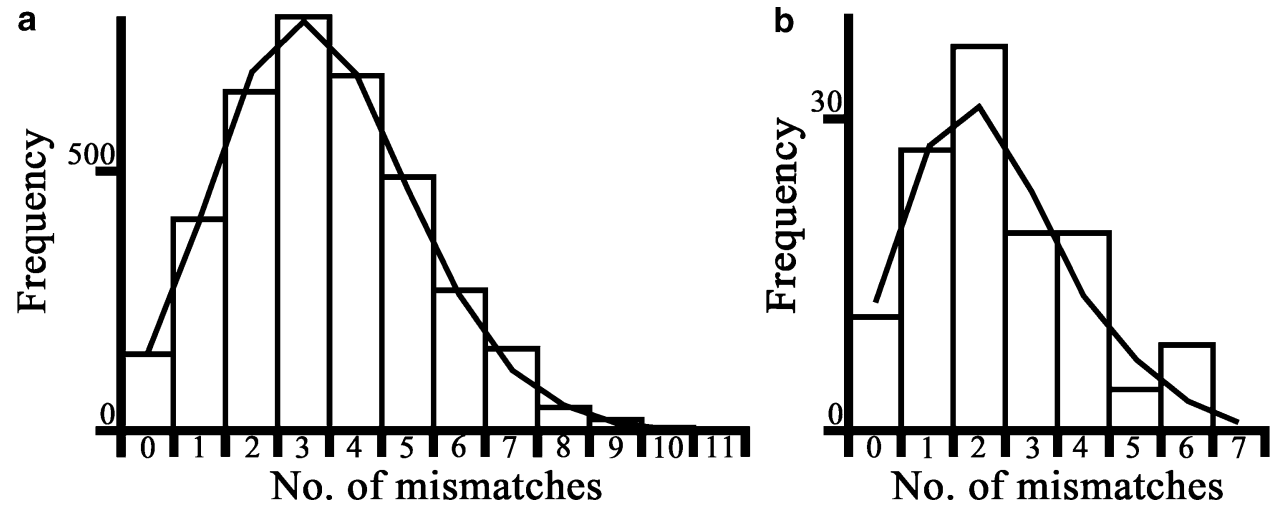

showed an apparent difference in geographic distribution. While the Group 1 was evenly distributed over the five study sites, the Group 2 was rare at the northernmost Alice Springs site. An average genetic distance of 0.015 (K2P) between the two haplotype groups was larger than the average distance between all pairs of individuals (0.007). By applying the average distance of 0.003 for the COI gene between the same pairs and its suggested rate of $0.67 \% / \mathrm{My}$ (see above), the evolutionary rate for the tRNA ${ }^{\text {Met }}-12 \mathrm{~S}$ rRNA region was calculated to be $1.56 \% / \mathrm{My}$ and hence the divergence between the Groups 1 and 2 at $0.958 \mathrm{Ma}$.

The mismatch distribution analysis showed that the Group 1 (mismatch observed mean $=3.413, \tau=3.479$, $\left.\theta_{0}=0.040, \theta_{1}=100.625, \mathrm{SSD}=0.0001, p=0.980\right)$ and the Group 2 (mismatch observed mean $=2.250, \tau=2.270$, $\left.\theta_{0}=0.004, \theta_{1}=99,999.000, \mathrm{SSD}=0.0080, p=0.480\right)$ have recently experienced sudden expansions in population size (Fig. 26.3). Using the calculated rates of the COI gene and the tRNA ${ }^{\text {Met }}-12 \mathrm{~S}$ rRNA region, the expansions of the Group 1 and the Group 2 were estimated to have occurred at 0.264 and $0.172 \mathrm{Ma}$, respectively. Tajima's $D(-2.071$ and -1.700 , respectively) and Fu's $F_{\mathrm{s}}(-27.34$ and -3.446 , respectively) were significantly negative for both groups ( $p<0.05$ ), also suggesting the recent expansions.

The average and standard deviation of mode values of the distributions of the posterior probabilities for the deviation date between the Groups 1 and 2 (i.e., the most probable estimates) among 10 runs was $5.23 \pm 3.52$ and seven of ten replicate runs showed the mode values around 5.0. The average genetic distance between all pairs of available 


\section{$1 \mathrm{Ma}$}

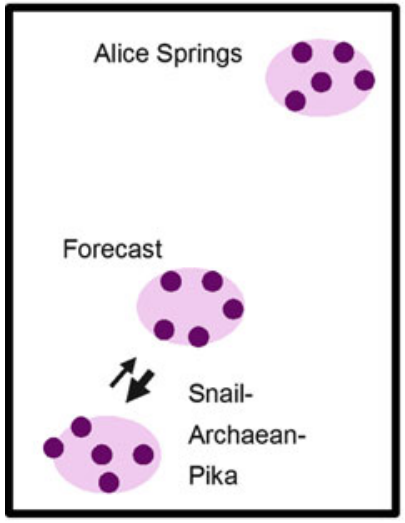

Decrease of hydorthermal

activity in the central and

southern MarianaTrough

Isolation of local

populations between two

regions

$0.3 \mathrm{Ma}$

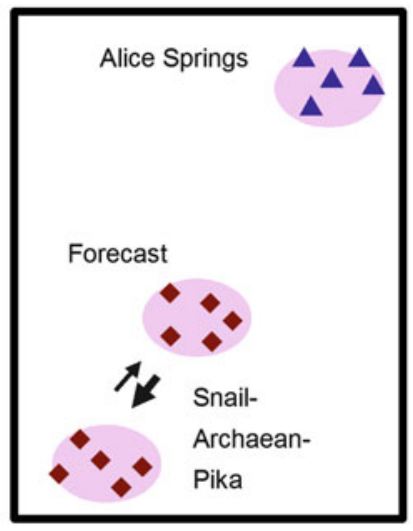

Genetic deviation of local

populations between the

central and southern Mariana

Trough



Increase of hydrothermal

activity in the central

Mariana Trough

Gene flow from the central

Mariana Trough to the

southern Mariana Trough
$0.2 \mathrm{Ma}$



Increase of hydrothermal

activity in the southern

Mariana Trough

Gene flow between the central and southern

Mariana Trough

Fig. 26.4 Estimated population history of Alviniconcha hessleri in the Mariana Trough between 1 and 0.2 million years ago (Ma)

individuals was 0.011 for the ATPS $\beta$ gene. Extrapolation of the average distance and substitution rate for the COI gene implied that this intron region has a rate of $2.46 \% / \mathrm{My}$. The estimated age of divergence between the two groups, $0.937 \mathrm{Ma}$, agreed well with the result inferred from the average genetic distance for the tRNA ${ }^{\text {Met }}-12 \mathrm{~S}$ rRNA region (0.958 Ma).

\subsection{Discussion}

The genetic distances estimated based on nucleotide sequences of the COI gene from the six individuals of Alviniconcha and three of Ifremeria nautilei, were approximately 1.9 times larger than that based on a single species for each genus (0.44) (Johnson et al. 2010), which suggests the saturation of genetic distance due to multiple substitutions at the same sites since the split between Alviniconcha and Ifremeria. The molecular evolutionary rate calculated based on such a more reasonable estimation is expected to enable reconstruction of reliable population history of Alviniconcha hessleri.

Population dynamics of hydrothermal-vent endemic species such as A. hessleri are thought to be controlled primarily by fluctuating hydrothermal activity. A decline in the activity results in the reduction of population size which accelerates divergence between local populations. In contrast, recovery of the activity causes an expansion of population size, fusion of isolated populations, and secondary contact between genetically differentiated individuals. Population divergence around $1 \mathrm{Ma}$ and expansions around 0.3 and $0.2 \mathrm{Ma}$, which were estimated for A. hessleri in the present study, are also attributable to changes in the hydrothermal activity (Fig. 26.4). Hydrothermal activities in the Mariana Trough, which started around $7 \mathrm{Ma}$ (Stern et al. 2003), are thought to have been more intense during its young stage than the present and therefore A. hessleri might have been distributed over a wider area in the trough. The present results showed genetic differentiation between populations in the central and southern parts of the Mariana Trough at around $1 \mathrm{Ma}$. The decline in hydrothermal activity might have resulted in the reduction of local populations of the species and loss of connectivity between them, which possibly represent the origin of the Groups 1 and 2.

The mismatch distribution analysis suggested that the Groups 1 and 2 expanded at 0.3 and $0.2 \mathrm{Ma}$, respectively. These expansion events might be attributable to the recovery of the local hydrothermal activity. In that case, the increase of the activity in the central Mariana Trough preceded that in the southern Mariana Trough and gene flow from expanding central population into southern ones might have predominated for about a 100,000 years and resulted in ubiquitous distribution of individuals of the Group 1. In contrast, the more recent increase of the population size in the southern Mariana Trough might have resulted in the uneven geographical distribution of individuals of the Group 2 (Fig. 26.3). 
The snails of Alviniconcha are one of the representative animal groups in the hydrothermal vent fields of the Pacific and Indian Oceans. Due to their dominance and strict endemism to the hydrothermal vent environment, which means their local populations change reflecting hydrothermal activities clearly, they are expected to be useful model animals for the evaluation of effects of artificial or natural environmental change such as those by the hydrothermal deposit mining or volcanic eruption on this deep-sea ecosystem. The general biology and natural history of these species have been the subject of several studies. For example, their spatial distribution within a single vent field and species compositions at different fields have been reported in the Lau Basin in the southern Pacific (Podowski et al. 2009; Beinart et al. 2012). Similar studies have been conducted for the closely related Ifremeria nautilei in the Manus Basin (Thaler et al. 2011). Information about the effects of the past environmental changes on the populations of such model species will be very useful for the interpretation of results of monitoring their genetic characteristics after the environmental change.

The history of hydrothermal ecosystems can be better reconstructed by comparing and integrating estimates of past environmental changes from biological and geochemical methodologies. Such studies are expected to contribute to more accurate reconstruction of history of hydrothermal ecosystems. Unfortunately, the present results cannot be compared with geochemical evidence. The historical fluctuation in the hydrothermal activity of the Mariana Trough have been traced back only to 12,000 years ago by the geochemical approach (Stüben et al. 1994; Takamasa et al. 2013, Ishibashi et al., Chap. 23), while our results suggested environmental changes between 1 to $0.2 \mathrm{Ma}$. Future progress in both methodologies will enable us to further explore the hypothesis that historical changes in hydrothermal activity promote genetic structuring of hydrothermal vent-endemic species.

\subsection{Acknowledgements}

Acknowledgements The authors are grateful to the operation teams of the submersible SHINKAI 6500, the crew of the support ship Yokosuka, and the onboard scientists of the YK10-11 cruise of Yokosuka for their help in sampling. This study was conducted as an activity of the scientific research innovative areas "TAIGA (Trans-crustal Advection \& In situ bio-geochemical processes of Global sub-seafloor Aquifer)" which is sponsored by Ministry of Education, Culture, Sports, Science and Technology (MEXT), Japan (No. 20109004).

Open Access This chapter is distributed under the terms of the Creative Commons Attribution Noncommercial License, which permits any noncommercial use, distribution, and reproduction in any medium, provided the original author(s) and source are credited.

\section{References}

Bandelt HJ, Forster P, Röhl A (1999) Median-joining networks for inferring intraspecific phylogenies. Mol Biol Evol 16:37-48

Beinart RA, Sanders JG, Faure B, Sylva SP, Lee RW, Becker EL, Gartman A, Luther GW III, Seewald JS, Fisher CR, Girguis PR (2012) Evidence for the role of endosymbionts in regional-scale habitat partitioning by hydrothermal vent symbioses. Proc Natl Acad Sci USA 109:E3241-E3250

Excoffier L, Lischer HEL (2010) Arlequin suite ver 3.5: a new series of programs to perform population genetics analyses under Linux and Windows. Mol Ecol Resour 10:564-567

Folmer O, Black M, Hoeh W, Lutz RA, Vrijenhoek RC (1994) DNA primers for amplification of mitochondrial cytochrome c oxidase subunit I from diverse metazoan invertebrates. Mol Mar Biol Biotech 3:294-299

Fu YX (1997) Statistical tests of neutrality of mutations against population growth, hitchhiking and background selection. Genetics 147:915-925

Hey J, Nielsen R (2007) Integration within the Felsenstein equation for improved Markov chain Monte Carlo methods in population genetics. Proc Natl Acad Sci USA 104:2785-2790

Hey J, Wakeley J (2001) Distinguishing migration from isolation: a Markov Chain Monte Carlo approach. Genetics 158:885-896

Hidaka H, Watanabe H, Kano Y, Kojima S (2013) Mitochondrial genome rearrangement in a hydrothermal vent-endemic lineage of provannid gastropods provides a new DNA marker for phylogeographical studies. J Mar Biol Assoc UK 93:1053-1058

Ho SYW, Shapiro B (2011) Skyline-plot methods for estimating demographic history from nucleotide sequences. Mol Ecol Resour $11: 423-434$

Ishibashi J, Nakai S, Toyoda S, Kumaga H, Noguchi T, Ishizuka O (2009) Geochemical and geochronological studies on the evolution of submarine hydrothermal systems. J Geogr 118:1186-1204 (in Japanese with English abstract)

Jarman SN, Ward RD, Elliott NG (2002) Oligonucleotide primers for PCR amplification of coelomate introns. Mar Biotechnol 4:347-355

Johnson L, Fryer H, Masuda H, Ishii T, Gamo T (1993) Hydrothermal deposits and two magma sources for volcanoes near $13^{\circ} 20^{\prime} \mathrm{N}$ in the Mariana backarc: a view from Shinkai 6500. EOS Trans AGU 74, Fall Meet Suppl, 381

Johnson SB, Warén A, Lee RW, Kano Y, Kaim A, Davis A, Strong EE, Vrijenhoek RC (2010) Rubyspira, a new genus and two new species of bone-eating deep-sea snails with ancient habits. Biol Bull 219:166-177

Kakegawa T, Utsumi M, Marumo K (2008) Geochemistry of sulfide chimneys and basement pillow lavas at the southern Mariana Trough $\left(12.55^{\circ} \mathrm{N}-12.58^{\circ} \mathrm{N}\right)$. Res Geol 58:249-266

Kimura M (1980) A simple method for estimating evolutionary rate of base substitutions through comparative studies of nucleotide sequence. J Mol Evol 16:111-120

Kojima S, Segawa R, Fujiwara Y, Fujikura K, Ohta S, Hashimoto J (2001) Phylogeny of hydrothermal vent-endemic gastropods Alviniconcha spp. from the Western Pacific revealed by mitochondrial DNA sequences. Biol Bull 200:298-304

Kuhner MK (2008) Coalecent genealogy samples: window into population history. Trends Ecol Evol 24:86-93

Okutani T, Ohta S (1988) A new gastropod mollusk associated with hydrothermal vents in the Mariana Back-Arc Basin, western Pacific. Venus (Jap J Malac) 47:1-9

Podowski EL, Moore TS, Zelnio KA, Luther GW III, Fisher CR (2009) Distribution of diffuse flow and megafauna in two sites on the Eastern Lau Spreading Center, Tonga. Deep-Sea Res I 56:2041-2056 
Raymond M, Rousset F (1995) An exact test for population differentiation. Evolution 49:1280-1283

Rogers AR (1995) Genetic evidence for a Pleistocene population explosion. Evolution 49:608-615

Rogers AR, Harpending H (1992) Population growth makes waves in the distribution of pairwise genetic differences. Mol Biol Evol 9:552-569

Rogers AD, Tyler PA, Connelly DP, Copley JT, James R, Larter RD, Linse K, Mills RA, Garabato AN, Pancost RD, Pearce DA, Polunin NVC, German CR, Shank T, Boersch-Supan XPH, Alker BJ, Aquilina A, Bennett SA, Clarke A, Dinley RJJ, Graham AGC, Green DRH, Hawkes JA, Hepburn L, Hilario A, Huvenne VAI, Marsh L, Ramirez-Llodra E, Roterman CN, Thatje S, Zwirglmaier $\mathrm{K}$ (2012) The discovery of new deep-Sea hydrothermal vent communities in the southern ocean and implications for biogeography. PLoS One 10:e1001234

Ronquist F, Huelsenbeck JP (2003) MRBAYES 3: Bayesian phylogenetic inference under mixed models. Bioinformatics 19:1572-1574

Shimayama T, Himeno H, Sasuga J, Yokobori S, Ueda T, Watanabe K (1990) The genetic code of a squid mitochondrial gene. Nucleic Acids Symp Ser 22:77-78

Stern RJ, Fouch MJ, Klemperer SL (2003) An overview of the IzuBonin-Mariana subduction factory. In: Eiler J, Hirschmann M (eds) Inside the subduction factory. American Geological Union, Washington, DC, pp 175-222

Stüben D, Taibi NE, McMurtry GM, Scholten J, Stoffers P, Zhang D (1994) Growth history of a hydrothermal silica chimney from the Mariana backarc spreading center (southwest Pacific, $18^{\circ} 21^{\prime} \mathrm{N}$ ). Chem Geol 113:273-296

Suzuki Y, Kojima S, Sasaki T, Suzuki M, Utsumi T, Watanabe H, Urakawa H, Tsuchida S, Nunoura T, Hirayama H, Takai K, Nealson
KH, Horikoshi K (2006) Host-symbiont relationships in hydrothermal vent gastropods of the genus Alviniconcha from the Southwest Pacific. Appl Environ Microbiol 72:1388-1393

Tajima F (1983) Statistical method for testing the neutral mutation hypothesis by DNA Polymorphism. Genetics 105:585-595

Takamasa A, Nakai S, Sato F, Toyoda S, Banerjee D, Ishibashi J (2013) U-Th radioactive disequilibrium and ESR dating of a baritecontaining sulfide crust from South Mariana Trough. Quat Geochronol 15:38-46

Thaler AD, Zelnio K, Saleu W, Shultz TF, Carlsson J, Cunnungham C, Vrijenhoek RC, Van Dover CL (2011) The spatial scale of genetic subdivision in populations of Ifremeria nautilei, a hydrothermalvent gastropod from the southwest Pacific. BMC Evol Biol 11:372

Urabe T, Ishibashi J, Maruyama A, Marumo K, Seama N, Utsumi M (2004) Discovery and drilling of on- and off-axis hydrothermal sites in backarc spreading center of southern Mariana Trough, western Pacific. EOS Trans AGU 85, Fall Meet Suppl, F1907

Vrijenhoek RC (2010) Genetic diversity and connectivity of deep-sea hydrothermal vent metapopulations. Mol Ecol 19:4391-4411

Weir BS, Cockerham CC (1984) Estimating $F$-statistics for the analysis of population structure. Evolution 38:1358-1370

Wheat CG, Fryer P, Hulme SM, Becker NC, Curtis A, Moyer C (2003) Hydrothermal venting in the southern most portion of the Mariana backarc spreading center at 12.57 degrees N. EOS Trans AGU 84, Fall Meet Suppl, F1399

Wilke T (2003) Salenthydrobia gen. nov. (Rissooidea: Hydrobiidae): a potential relic of the Messinian salinity crisis. Zool J Linn Soc 137:319-336

Yoshikawa S, Okino K, Asada M (2012) Geomorphological variations at hydrothermal sites in the southern Mariana Trough Relationship between hydrothermal activity and topographic characteristics. Mar Geol 303-306:172-182 